\title{
Ultrasonography for chairside evaluation of periodontal structures: A pilot study
}

\author{
Mustafa Tattan' ${ }^{1}$ iD | Khaled Sinjab ${ }^{2} \quad$ Eunjee Lee ${ }^{3} \quad$ Michelle Arnett $^{4}$ | Tae-Ju Oh \\ Hom-Lay Wang' iD | Hsun-Liang Chan² iD | Oliver D. Kripfgans ${ }^{5,6}$ (iD
}

${ }^{1}$ Department of Periodontics and Iowa Institute for Oral Health Research, University of Iowa College of Dentistry, Iowa City, IA, USA

${ }^{2}$ Department of Periodontics and Oral Medicine, University of Michigan School of Dentistry, Ann Arbor, MI, USA

${ }^{3}$ Department of Information and Statistics, Chungnam National University, Daejoen, South Korea

${ }^{4}$ Department of Primary Dental Care, Division of Dental Hygiene, University of Minnesota, Minneapolis, MN, USA

${ }^{5}$ Department of Radiology, University of Michigan Medical School, Ann Arbor, MI, USA

${ }^{6}$ Department of Biomedical Engineering, College of Engineering, Ann Arbor, MI, USA

\section{Correspondence}

Hsun-Liang Chan, Clinical Associate Professor, Department of Periodontics and Oral Medicine, University of Michigan School of Dentistry, 1011 N. University Avenue, Ann Arbor, MI48109, USA.

Email:hlchan@umich.edu

\begin{abstract}
Background: The crestal bone level and soft tissue dimension are essential for periodontal diagnosis and phenotype determination; yet, existing measurement methods have limitations. The aim of this clinical study was to evaluate the correlation and accuracy of ultrasound in measuring periodontal dimensions, compared to direct clinical and cone-beam computed tomography (CBCT) methods.
\end{abstract}

Methods: A 24-MHz ultrasound probe prototype, specifically designed for intraoral use, was employed. Periodontal soft tissue dimensions and crestal bone levels were measured at 40 teeth and 20 single missing tooth gaps from 20 patients scheduled to receive a dental implant surgery. The ultrasound images were interpreted by two calibrated examiners. Inter-rater agreement was calculated by using inter-rater correlation coefficient (ICC). Ultrasound readings were compared with direct clinical and CBCT readings by using ICC and Bland-Altman analysis.

Results: The following six parameters were measured: 1$)$ interdental papilla height (tooth), 2) mid-facial soft tissue height (tooth), 3) mucosal thickness (tooth), 4) soft tissue height (edentulous ridge), 5) mucosal thickness (edentulous ridge), and 6) crestal bone level (tooth). Intra-examiner calibrations were exercised to achieve an agreement of at least 0.8 . ICC between the two readers ranged from 0.482 to 0.881 . ICC between ultrasound and direct readings ranged from 0.667 to 0.957 . The mean difference in mucosal thickness (tooth) between the ultrasound and direct readings was $-0.015 \mathrm{~mm}$ ( $95 \%$ CI: -0.655 to $0.624 \mathrm{~mm}$ ) without statistical significance. ICC between ultrasound and CBCT ranged from 0.654 to 0.849 among the measured parameters. The mean differences between ultrasound and CBCT range from -0.213 to $0.455 \mathrm{~mm}$, without statistical significance.

Conclusion: Ultrasonic imaging can be valuable for accurate and real-time periodontal diagnosis without concerns about ionizing radiation.

\section{K E Y W O R D S}

alveolar ridge, bone, cone-beam computed tomography, dental implants, periodontium, ultrasonography 


\section{1 | INTRODUCTION}

Ultrasound was proposed to image periodontal soft and hard tissues in as early as the 1970s, owing to its non-ionizing, real-time, and cost-effective properties. ${ }^{1}$ It functions by transmitting sound waves from the ultrasound probe through a medium, and recording time-dependent reflections from tissue structures (object). On the basis of the travel time and the speed of sound, the distance between the probe and the object can then be determined. Primarily designed for soft tissue evaluation, ultrasound was validated for measuring soft tissue thickness in various anatomical locations of the oral cavity. ${ }^{2-6}$ However, a single element ultrasound device was used in these studies, meaning that only values of soft tissue thickness were derived, as opposed to images. Efforts have also been made to design an ultrasonic device to identify periodontal attachment level. ${ }^{7}$ This device has a probe that directs sound waves into pockets with water for coupling. A computer algorithm could then identify the junction of the periodontal ligament and gingival connective tissue due to the impedance difference between the two structures. A recent study ${ }^{8}$ applied ultrasound in the measurement of facial soft tissue thickness changes around implants following connective tissue graft procedures. Two studies demonstrated accurate periodontal images using a one-dimensional ultrasound array. ${ }^{9}, 10$

As for periodontal hard tissue evaluation, an ophthalmic ultrasound device was previously used to define alveolar bone topography intraorally in four participants. ${ }^{11}$ Low image resolution unfortunately resulted in inaccurate alveolar bone measures. On the other hand, higher frequency, that is, higher image resolution, ultrasound probes showed promising outcomes in cadaverous porcine models. ${ }^{12-15} \mathrm{~A}$ human cadaver study ${ }^{16}$ reconstructed 3-dimensional (3D) jawbone surface image for the diagnosis of periodontal bony defects and a recent study of our group presented proof-ofprinciple, that ultrasound can image oral structures, including periodontal hard and soft structures on a human cadaver. ${ }^{17}$ Another study demonstrated accurate ultrasound readings of alveolar bone height and thickness with cadaverous human specimens. ${ }^{18}$ In this study, a probe for general purposes (center frequency of $14 \mathrm{MHz}$ ) was used. The mean absolute differences of ultrasound measures from direct measures and cone-beam computed tomography (CBCT) radiographic measures are within $0.1 \mathrm{~mm}$. A recent meta-analysis provides preliminary evidence to support ultrasound for measuring alveolar bone level. ${ }^{19}$ By collaborating with an ultrasound scanner manufacturer, a prototype dental ultrasound probe was made. Satisfactory accuracy was demonstrated by using this prototype to measure peri-implant tissue dimensions on human cadavers. ${ }^{20}$ The mean absolute differences between ultrasound and direct/CBCT measurements range from 0.033 to $0.24 \mathrm{~mm}$. For the first time, we validated in human participants this dental ultrasound prototype for assessing periodontal structures. The primary aim is to compare ultrasound soft and hard periodontal and edentulous ridge tissue dimensions to direct- and CBCT measurements.

\section{2 | MATERIALS AND METHODS}

\section{1 | Recruitment}

This study was approved by the University of Michigan Institutional Review Board (Study ID: HUM00099062) and was conducted in accordance with the Helsinki Declaration of 1975, as revised in 2013. It was registered at ClinicalTrials.gov (Study ID: NCT03657589). All patients signed an informed written consent to participate in the study. A sample of 20 participants scheduled for a single implant surgery, at the University of Michigan School of Dentistry, Department of Periodontics and Oral Medicine, were recruited for this pilot study. The participants were deemed eligible if they had a maxillary or mandibular single edentulous area at the anterior or premolar site with two immediately adjacent teeth on both sides available. The sites of interest in each individual patient were the mesial and distal tooth, in addition to the edentulous site for an implant placement.

\subsection{Quantitative data acquisition}

The following six parameters were measured and compared (Fig. 1): 1) Interdental papilla height (PH): the vertical distance from the tip of the facial papilla to the crestal bone on the mesial and distal papillae of a given tooth. 2) Mid-facial soft tissue height at teeth $(\mathrm{STHt})$ : the vertical distance from the free gingival margin to the crestal bone at the mid-facial site of a given tooth. 3) Mucosal thickness at teeth (MTt): the horizontal distance between the mucosal surface and the underlying bone or root surface measured at 2 and $5 \mathrm{~mm}$ from the gingival margin at mid-facial sites. 4) The crestal bone level (CBL) at teeth: the vertical distance between the alveolar crest and the cemento-enamel junction (CEJ) or the restoration margin on the mid-facial site of the imaged tooth. 5) Soft tissue height at the edentulous ridge (STHe): the vertical distance from the external border of the cortical bone to the most superficial level of the crestal soft tissue in the center of the gap. 6) Mucosal thickness at the edentulous ridge (MTe): the horizontal distance between the mucosal surface to the underlying bone surface, measured at 3 and $6 \mathrm{~mm}$ from the mucosal margin at mid-facial and mid-palatal sites.

\section{3 | CBCT scans}

CBCT scans were acquired for participants who did not have a clinically ordered scan for the planned implant surgeries. The CBCT scans were used to acquire crestal bone levels and 


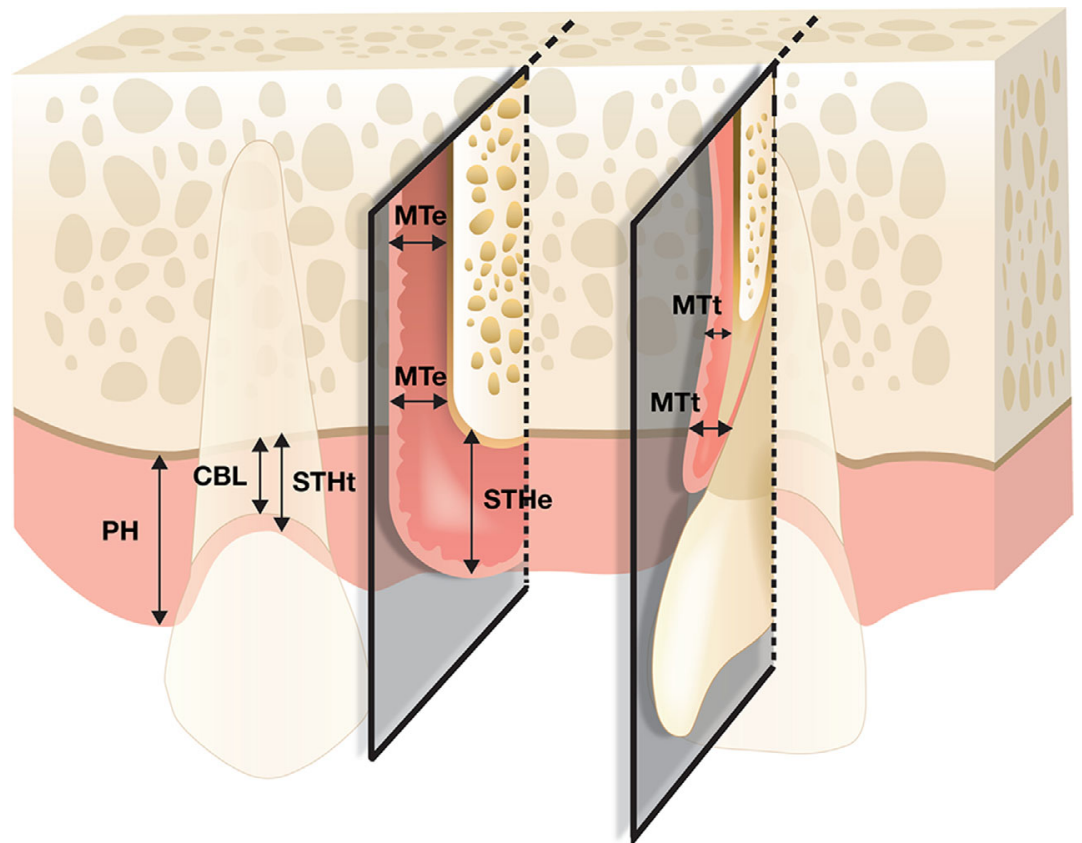

F I G U R E 1 Illustrations depicting the parameters described in the methodology, including interdental papilla height $(\mathrm{PH})$, crestal bone level (CBL), mucosal thickness at teeth (MTt), soft tissue height at the edentulous ridge (STHe) and mucosal thickness at the edentulous ridge (MTe) soft tissue-related parameters as an additional reference for comparison with ultrasound readings. All scans, regardless of being clinical or research-related, were obtained using a CBCT device, ${ }^{*}$ with scanning parameters of $120 \mathrm{kVp}$, $18.66 \mathrm{mAs}$, scan time of 20 seconds, and resolution of $250 \mu \mathrm{m}$. The captured CBCT scans were reconstructed in 3D using the built-in software, saved in digital imaging and communications in medicine (DICOM) format, and subsequently exported into commercially available implant-planning software $^{\dagger}$ for measurements by two calibrated examiners (MT and KS).

\section{4 | Ultrasound scans}

The ultrasound scan was a separate visit usually within 2 weeks before the implant surgery date when direct measurements were made. A single examiner (HC) performed the ultrasound scanning procedure using the $24 \mathrm{MHz}$ imaging probe prototype, while a second examiner $(\mathrm{OK})$ specialized in ultrasound imaging operated the ultrasound scanner. ${ }^{*}$

The scanning set-up and procedure has been described in previous publications. ${ }^{17,18}$ Briefly, the probe prototype dimension is comparable to that of a toothbrush and its cable runs perpendicular to the aperture, allowing for crosssectional scans to the second molars. The maximal transducer thickness, width and length is $15,16.2$, and $30 \mathrm{~mm}$. Its axial and lateral image resolution is 64 and $192 \mu \mathrm{m}$, respectively, with an optimal penetration depth of $15 \mathrm{~mm}$, and in real-time image acquisition. To enhance image resolution of

\footnotetext{
*3D Accuitomo 170, JMorita, Tokyo, Japan.

Invivo5, Anatomage Dental, San Jose, CA.

$\ddagger$ ZS3, Zonare/Mindray, Mountain View CA.
}

bone and tooth edges, a built-in function for spatial compounding was selected. Acoustic coupling was achieved with mounting a gel-based stand-off-pad ${ }^{\S}$ to the probe aperture and applying ultrasound gel between the pad and the oral structures. The mesial and distal teeth adjacent to the edentulous gap in each participant were scanned at the mesial and distal papillae and mid-facial surface with the transducer placed approximately in line with the long axis of the particular tooth (Fig. 2). The included edentulous gaps were scanned at the mid-facial and mid-lingual surfaces. The participants wore a customized acrylic reference guide during the ultrasound scans. The same guide was used during the CBCT scan and direct measurements to minimize measurement site variability among the three methods. Several ultrasound scans with minute differences in the facio-lingual scan plane in relationship to the teeth were acquired to capture the anatomical structures needed for linear tissue quantification and saved in digital imaging and communications in medicine (DICOM). ultrasound readings were performed in millimeters via commercially available software ${ }^{\text {II }}$ with a built-in caliper accurate to $0.01 \mathrm{~mm}$ by two independent, calibrated investigators (MT and $\mathrm{KS}$ ).

At the implant placement visit, before elevating a full thickness flap, the papilla and mucosal height of teeth and mucosal thickness at the dentate and edentulous sites were measured by a calibrated examiner (HC). Soft tissues in situ before flap elevation facilitated easier and more accurate measurements. Interdental papilla height and facial mucosal height around teeth were measured with a calibrated periodontal probe ${ }^{\#}$ to

\footnotetext{
§ Aquasonic, Parker, PA.

II Osirix, Bernex, Switzerland.

\# University of North Carolina (UNC) Probe, Hu-Friedy, Chicago, IL.
} 
F I G U R E 2 Implant treatment planning clinical photographs (A through C), with corresponding ultrasound images (D through $\mathbf{F}$ ). B = bone surface, $\mathrm{C}$ = crown surface, $\mathrm{L}=$ lip, $\mathrm{R}=$ root surface, $\mathrm{ST}=$ soft tissues
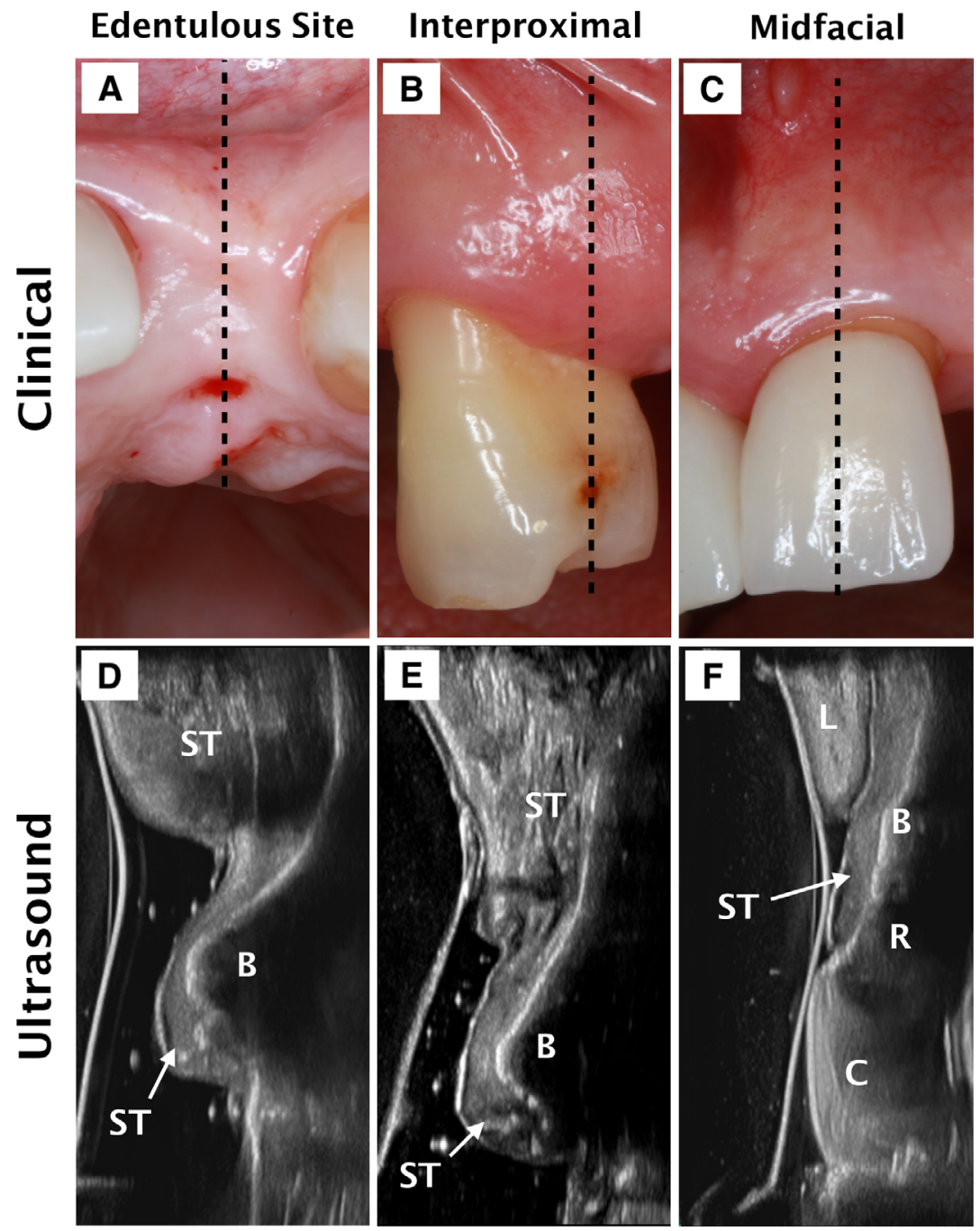

the closest $0.5 \mathrm{~mm}$. Both parameters were measured from the respective soft tissue margin to the crestal bone. After facial flap elevation, the remaining measurements (i.e., the mucosal height at the edentulous gap and crestal bone level) were made with the same periodontal probe.

To clinically measure mucosal thickness, a \#25 endodontic file was penetrated into the mucosa at the corresponding sites until bone/tooth root resistance was detected, during which the rubber stop was positioned in contact with the mucosal surface. The file was inserted perpendicular to the mucosal surface. The distance between the tip of the file to the rubber stop (i.e., the mucosal thickness) was measured using a metric digital caliper, precision to $0.01 \mathrm{~mm}$.

\section{5 | Intra-examiner and inter-examiner calibration}

The two readers (MT and KS) for ultrasound and CBCT images were first calibrated with the gold standard reader (HC) using two randomly selected cases in 1 day delay, to allow for memory washout, until an agreement of at least 0.8 was achieved. ${ }^{21}$ Subsequently, intra-examiner calibration of the ultrasound and $\mathrm{CBCT}$ readings were performed in the same way. Intra-examiner calibration of direct measurements was performed in a previous study, with an agreement of $0.8^{20}$

\section{6 | Data analysis}

A masked biostatistician (EL) performed statistical analysis. The inter-rater correlation coefficients (ICC), root mean square error (RMSE) and maximum differences were calculated to evaluate the strength of agreement between ultrasound measurements from both readers. The pairwise agreement between the direct, ultrasound and CBCT measurements were also assessed by ICC. ${ }^{22}$ Because six hypotheses were tested to examine whether or not the agreement is strong enough for the six parameters listed above, Bonferroni corrections were used to adjust the significance level as $0.0083(=0.05 / 6) . F$ tests were used to examine if the $P$ values of the ICC were significantly $>0$. The ICC ranges from -1 to 1 , where an estimate of 1 indicates perfect agreement and 0 means random agreement. Negative ICCs indicate a systematic disagreement. Commonly-cited cutoffs are poor 
T A B L E 1 Inter-rater agreement of the two examiners for each of the study parameters measured via ultrasound and CBCT depicted as inter-rater correlation coefficients (ICC)

\begin{tabular}{|c|c|c|c|c|c|c|}
\hline \multirow[b]{2}{*}{ Parameter } & \multirow[b]{2}{*}{$\mathbf{n}$} & \multirow[b]{2}{*}{ Method } & \multirow[b]{2}{*}{ ICC } & \multicolumn{2}{|c|}{ 95\% Confidence interval } & \multirow[b]{2}{*}{$\boldsymbol{P}$} \\
\hline & & & & Lower & Upper & \\
\hline Interdental papilla height & 71 & Ultrasound & 0.818 & 0.724 & 0.882 & $<0.0001^{*}$ \\
\hline Mucosal thickness at teeth & 73 & Ultrasound & 0.776 & 0.493 & 0.912 & $0.0001 *$ \\
\hline Soft tissue height at the Edentulous Ridge & 17 & Ultrasound & 0.482 & 0.286 & 0.640 & $<0.0001^{*}$ \\
\hline Crestal bone level & 28 & $\mathrm{CBCT}$ & 0.965 & 0.926 & 0.984 & $<0.0001^{*}$ \\
\hline
\end{tabular}

* $=$ statistical significance, $P<0.05$

for ICC values $<0.40$, fair for values between 0.40 and 0.59 , good for values between 0.60 and 0.74 , and excellent for values between 0.75 and $1.0 .^{21}$ Bland-Altman plots were also created to evaluate the differences between ultrasound, direct measurements, and $\mathrm{CBCT}$ readings ${ }^{23}$ and clinical significance. All statistical analyses were conducted using statistical software.*

\section{3 | RESULTS}

\section{1 | Descriptive analysis}

A total of 20 participants (15 males and five females), with a mean age of $61.2 \pm 13.4$ years were included in this study. The study sample accounted for 40 teeth (anterior teeth [27] and posterior teeth [13] sites) and 20 edentulous ridges (anterior [16] and premolar [4]). Of these sites, 51 sites were in the maxilla (34 tooth sites and 17 edentulous sites), while nine were in the mandible (six tooth sites and three edentulous sites).

\section{2 | Inter-rater agreement}

Table 1 summarizes the inter-rater agreements on ultrasound measurements. ultrasound measurements of PH, STHt, MTt, MTe, and CBL had excellent agreement ( $\mathrm{ICC}=0.78$ to 0.88 ), except for STHe with fair agreement $(\mathrm{ICC}=0.48)$. Excellent agreement was demonstrated for CBCT derived CBL measurements, $(\mathrm{ICC}=0.97)$. Dual-investigator measurements were averaged for further analysis (ultrasound and CBCT).

\subsection{Pairwise correlation between ultrasound, direct, and CBCT readings}

Ultrasound soft tissue measurements demonstrated good agreement with direct measurements of STHe and MTt

\footnotetext{
${ }^{*} \mathrm{R}$ version 3.2.2, The $\mathrm{R}$ Foundation for Statistical Computing, Vienna, Austria.
}

(ICC $=0.667$ and 0.707 , respectively), and excellent agreement for the remaining parameters $(\mathrm{ICC}=0.829$ to 0.918) (Fig. 3). Excellent agreement was observed for both ultrasound and CBCT with direct CBL measurement (ICC $=0.957$ and 0.798 , respectively). When ultrasound soft tissue parameters were compared with CBCT, the resulting ICC values demonstrated good to excellent agreement $(0.654$ to 0.849 ) (Table 2). The RMSEs and maximum differences between ultrasound and direct measurements were reported in supplementary Table S1 in online Journal of Periodontology. The RMSEs range from 0.324 to $0.656 \mathrm{~mm}$ for the measured parameters except for soft tissue height at the edentulous ridge $(0.933 \mathrm{~mm})$. The average maximum differences show a similar pattern with values from the edentulous ridge being the greatest.

\section{4 । Bias and variability of ultrasound relative to direct and CBCT readings}

The mean differences and limits of agreement generated by the Bland-Altman plots were used to depict the clinical significance of the ultrasound measurements (Table 2). In each plot of Figure 4, the blue solid line represents the mean differences between the ultrasound and direct measurements, while the red dotted lines show the upper and lower $95 \%$ limits of agreement. Supplementary Figures S1 and S2 in online Journal of Periodontology illustrate the direct/CBCT and ultrasound/CBCT comparisons, respectively. Among the five soft tissue parameters, the smallest difference between ultrasound and direct readings is $0.015 \mathrm{~mm}$, found in the MTt measurements; whereas the largest mean difference is $0.48 \mathrm{~mm}$ for STHe measures. Similarly, the differences between ultrasound and CBCT soft tissue measurements were $0.213(\mathrm{MTt}), 0.351(\mathrm{PH})$ and $0.455(\mathrm{STHt}) \mathrm{mm}$. The mean difference in CBL for ultrasound/direct and ultrasound/CBCT is 0.078 and $0.412 \mathrm{~mm}$, respectively. All the six ultrasound parameters are not significantly different from the direct and CBCT readings $(P>0.05)$, suggesting there are no systematic deviations. 
A

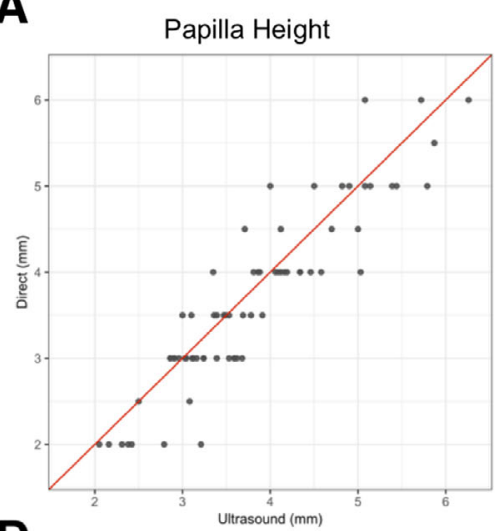

D

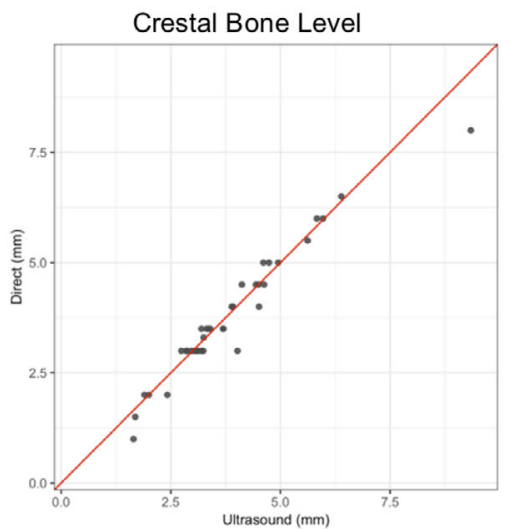

B

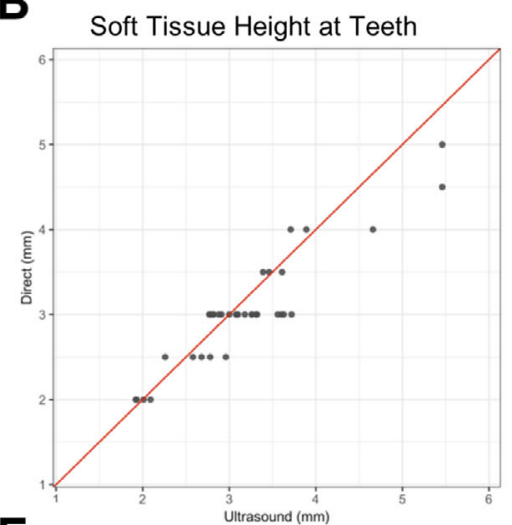

E
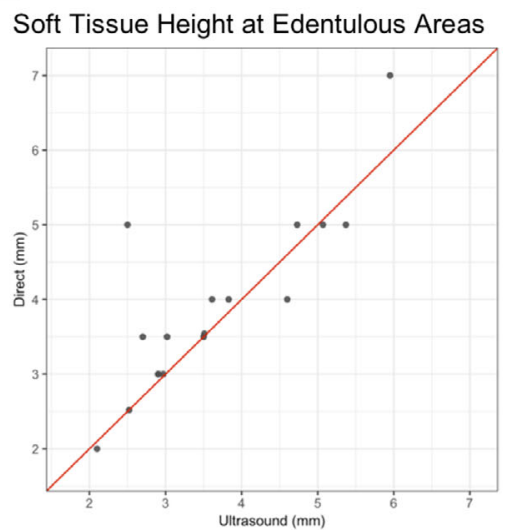

C

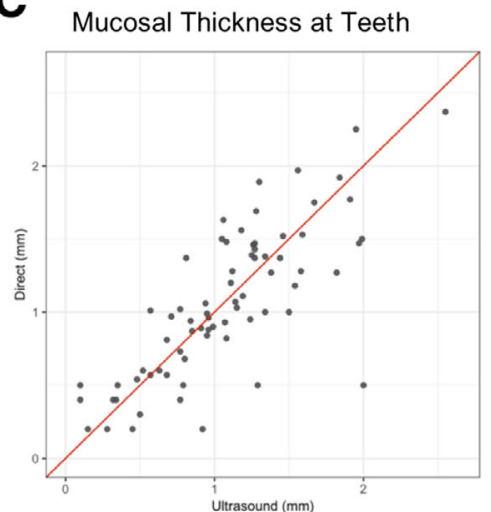

$\mathbf{F}$

Mucosal Thickness at Edentulous Areas

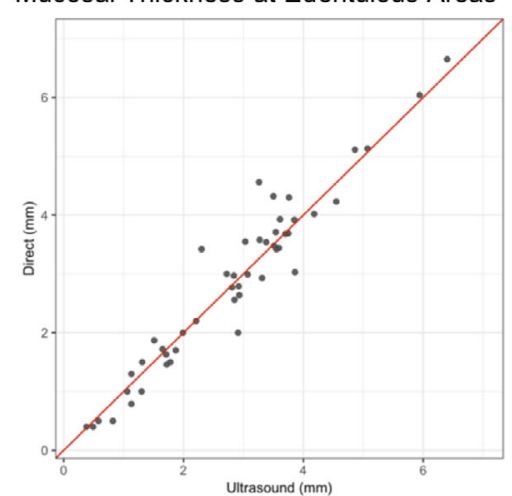

F I G U R E 3 Scatter plots depicting the correlation between ultrasound and direct measurements for each of the study parameters

T A B L E 2 Agreement between the methods of measurement (direct, ultrasound, and CBCT) depicted as inter-rater correlation coefficients (ICC) and mean differences

\begin{tabular}{|c|c|c|c|c|c|c|c|}
\hline Parameter & $\mathbf{n}$ & Subgroup & $\begin{array}{l}\text { Mean difference } \\
\text { (limits of agreement) }\end{array}$ & ICC & \multicolumn{2}{|c|}{$\begin{array}{l}\text { 95\% Confidence } \\
\text { interval }\end{array}$} & $\boldsymbol{P}$ \\
\hline \multirow[t]{2}{*}{ Interdental papilla height } & 68 & Ultrasound-Direct & $-0.076(-0.991$ to 0.840$)$ & 0.873 & 0.803 & 0.912 & $<0.0001^{*}$ \\
\hline & 45 & Ultrasound-CBCT & $0.351(-1.279$ to 1.981$)$ & 0.654 & 0.371 & 0.810 & $0.0003^{*}$ \\
\hline Soft tissue height at teeth & 36 & Ultrasound-Direct & $-0.159(-0.942$ to 0.623$)$ & 0.829 & 0.691 & 0.909 & $<0.0001^{*}$ \\
\hline \multirow[t]{2}{*}{ Mucosal thickness at teeth } & 69 & Ultrasound-Direct & $-0.015(-0.655$ to 0.624$)$ & 0.707 & 0.567 & 0.808 & $<0.0001^{*}$ \\
\hline & 45 & Ultrasound-CBCT & $-0.213(-1.052$ to 0.626$)$ & 0.657 & 0.377 & 0.812 & $0.0002^{*}$ \\
\hline Soft tissue height at the edentulous ridge & 16 & Ultrasound-Direct & $0.479(-1.138$ to 2.097$)$ & 0.667 & 0.284 & 0.868 & $0.0013^{*}$ \\
\hline Mucosal thickness at the edentulous ridge & 44 & Ultrasound-Direct & $0.127(-1.145$ to 1.398$)$ & 0.918 & 0.855 & 0.954 & $<0.0001^{*}$ \\
\hline
\end{tabular}

$*$ statistical significance, $P<0.05$

\section{4 | DISCUSSION}

\section{1 | Ultrasound accuracy relative to established methods}

This study is among the first, to the authors' best knowledge, to image periodontal tissues on live humans with ultrasound. ${ }^{9,10}$ The measurement accuracy generated by ultrasound imaging is categorized into two broad categories: soft tissue and hard tissue dimensions. For soft tissue dimensions, direct clinical measurements were considered the gold standard. Good to excellent correlations (0.657 to 0.918 ) of ultrasound soft tissue measures to the direct measures were 
A

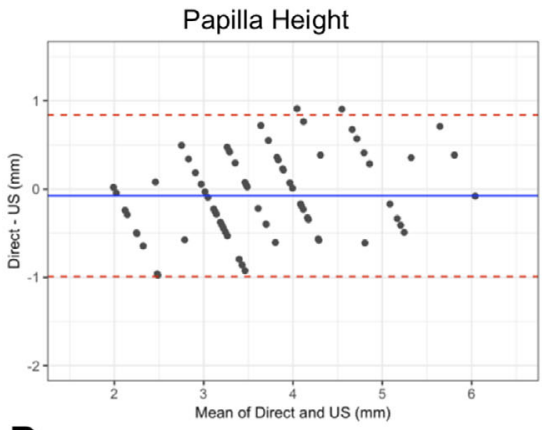

D

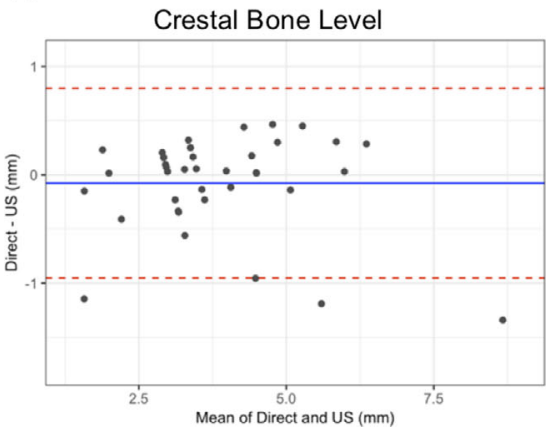

B

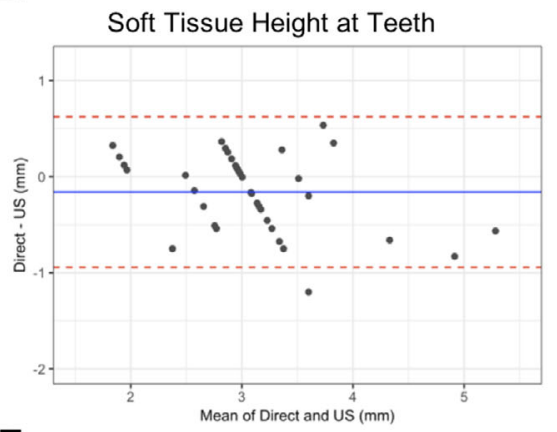

E

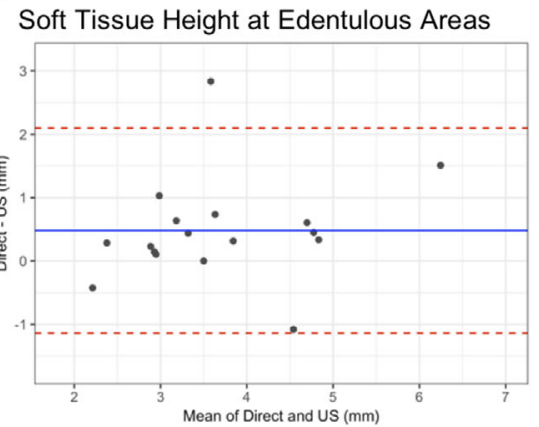

C

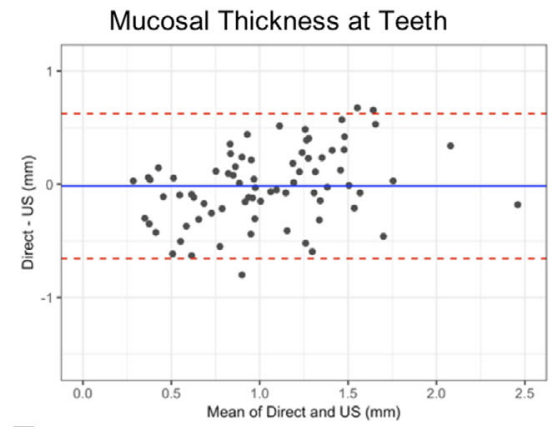

$\mathbf{F}$

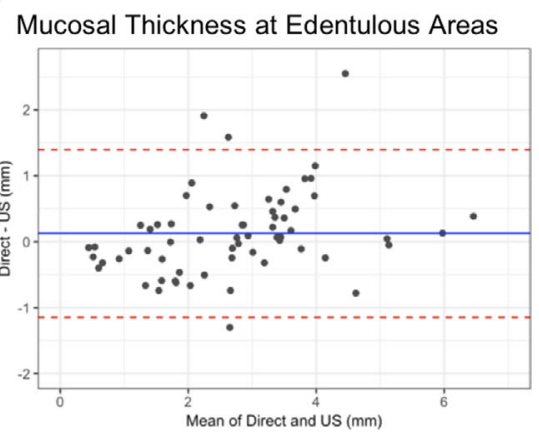

F I G U R E 4 Bland-Altman plots depicting the mean absolute differences of ultrasound measurements for each of the study parameters

obtained. Additionally, the mean differences of direct versus ultrasound soft tissue measurements range from -0.015 to $-0.159 \mathrm{~mm}$, with an exception of soft tissue height at the edentulous sites, which is $0.479 \mathrm{~mm}$. The limits of agreement (95\% CI) between ultrasound and direct interdental papilla height and mid-facial soft tissue height is -0.991 to $0.840 \mathrm{~mm}$ and -0.942 to $0.623 \mathrm{~mm}$. The limits of agreement between ultrasound and direct mucosal thickness at teeth is -0.655 to $0.624 \mathrm{~mm}$. The results are in general consistent with a recent human cadaver study. ${ }^{24}$ Overall the results suggest that ultrasound assessing periodontal soft tissue dimensions agrees with direct measurements. Variability between ultrasound and direct soft tissue dimension measures at edentulous ridge is greater, with the limits of agreement between 1 to $2 \mathrm{~mm}$. The primary reason for inconsistent soft tissue height measures at the edentulous sites is believed to be associated with the uneven ridge bone contour due to the use of bone allografts for ridge preservation in these cases. For hard tissue delineation, ultrasound measured crestal bone level was found to be highly correlated with direct measures. We also noticed that, ultrasound may differentiate thin alveolar bone better than CBCT. In approximately one third of the cases, CBCT is unable to locate the crestal bone level due to either a thin buccal plate or due to artifacts from metallic restoration materials (Table 1). These findings are in accordance with the results of our previous study. ${ }^{18}$ Inter-examiner agreements were between fair (ICC $=0.482$ for soft tissue height at edentulous ridge) and excellent (ICC ranges between 0.77 and 0.88 for the rest parameters) for ultrasound readings, possibly indicating a learning curve for this new dental imaging modality.

\section{2 | Clinical significance}

Alveolar bone loss is the hallmark of periodontal disease. Microbial dysbiosis in the periodontium elicits an inflammatory response, resulting in a reduction of collagen and mineral content within the alveolar bone, and eventually manifests as bone loss on radiographs. In a healthy periodontium, crestal bone level is on average 1 to $2 \mathrm{~mm}$ below the CEJ. When the reading is greater than this average, alveolar bone loss is suspected. Intra-oral radiographs only provide superimposed interproximal bone levels. The consequence is that periodontal destruction in the facial and palatal/lingual sites may be undiagnosed, especially in the molar regions with furcation involvement. Similarly, when using the free gingival margin as a reference, crestal bone level is located at 3 to $4 \mathrm{~mm}$ below the margin in a healthy periodontium. This dimension is composed of clinical probing depth, junctional epithelium, and connective tissue attachment. When the reading is beyond this normal range, periodontal tissue loss or gingival overgrowth is suspected. Therefore, the combined ultrasound crestal bone level readings using both the free gingival margin and a fixed reference point (i.e., CEJ) could provide value in the diagnosis of periodontal disease. Current scan times are 1 minute/tooth; in the future, an automated probe positioning system could be developed to aim for full-mouth scanning in 5 minutes. This way, it can provide a high-throughput screening 
of periodontal patients during the initial visit and follow-up visits as well. A series of standard full-mouth ultrasound scans then can be superimposed in a clinical setting, and the difference in bone levels compared for evaluating periodontal disease activity. The acceptance of this new technology by clinicians for use in a clinical setting will heavily depend on cost-benefit considerations, easiness of use, and if ultrasound scanning can be a reimbursable procedure, etc. Training acceptance is anticipated to be high. For this study, readers were calibrated within 2 weeks. This included machine (ultrasound scanner) use, scanning, and image interpretation. Image interpretation time is $<1$ minute/image.

In addition to diagnosing periodontal disease, ultrasound could be used to evaluate periodontal tissue phenotype. Tissue phenotype is considered an important determinant of clinical outcomes following periodontal disease treatment, ${ }^{25-28}$ bone regenerative procedures, ${ }^{29}$ and implant therapy. ${ }^{8,30-32}$ Various methods have been developed to evaluate soft tissue type, including both visual and probing methods. ${ }^{33,34}$ Ultrasound is an excellent tool for soft tissue evaluation and has been reportedly validated in the measurement of periodontal soft tissue thickness. ${ }^{2,3,24}$ Regarding hard tissue phenotype, the accuracy and reliability of CBCT has been studied using cadaveric specimens. ${ }^{35}$ However, due to resolution limitations, CBCT cannot differentiate thin facial bone, where most facial bone exhibits a thickness of $<1 \mathrm{~mm}$ in the maxillary anterior region. ${ }^{36-39}$ The current prototype has an axial resolution of $64 \mu \mathrm{m}$, which is superior to 250 to $500 \mu \mathrm{m}$ that commercially available CBCT machines can provide; therefore, ultrasound can complement radiographs in the measurement of facial bone thickness. ${ }^{18}$ However, ultrasound can only measure bone thickness at the alveolar crest due to ultrasound attenuation at the bone surface.

All participants in this study are either periodontally healthy or stable. Therefore, neither deep pockets nor irregular bony destruction (e.g., infrabony defects) are present in this cohort. The current device can reliably imagine up to $15 \mathrm{~mm}$ of the depth. To further validate ultrasound for evaluating periodontal tissues, patients with varying degrees of periodontal disease severity need to be imaged. In those patients, the scanning angle may need to be adjusted to a straighter angle towards the periodontal pockets in order for bony irregularities to be incorporated within the image. Additionally, anatomical imaging is only suitable for measuring tissue dimensions of interest; functional imaging is required to detect biological activity, for example, estimation of the blood flow. Ultrasound is capable of estimating the blood flow velocity and the amount of blood flow. ${ }^{40}$ Therefore, ultrasound may be able to differentiate healthy from the inflamed tissue, in which microvasculature homeostasis is disrupted. ${ }^{41}$ In addition, a new ultrasound-based imaging modality, photoacoustic imaging, may be useful in the fluctuation of minute changes in ratio of oxygenated/deoxygenated hemoglobin in periodontal tissues as a result of the presence of disease. ${ }^{42,43}$ Future research should focus on using photoacoustic imaging to evaluate disease activity, to allow for early intervention to be implemented for the purpose of minimizing tissue damage and maximizing treatment outcomes.

\section{5 | CONCLUSIONS}

With encouraging first time human data displaying satisfactory measurements of periodontal soft and hard tissue dimensions, ultrasound imaging could become a valuable tool for real-time, cross-sectional evaluation of the periodontia without concerns of ionizing radiation and metallic artifacts. Future research should focus on the ability of ultrasound to differentiate periodontal disease from healthy status.

\section{ACKNOWLEDGMENTS}

The authors would like to thank Dr. Erika Benavides, DDS, $\mathrm{PhD}$, Clinical Associate Professor, University of Michigan School of Dentistry, for providing CBCT services, and Ms. Alicia Baker, Clinic Coordinator and Cynthia Miller and Veronica Slayton, Dental Assistants, for assisting with this project. The study was supported by grants from the University of Michigan, Michigan Institute for Clinical and Health Research (MICHR) (UL1TR000433), Ann Arbor, Michigan; the Delta Dental Foundation (AWD004687), Okemos, Michigan; the Osteology Foundation (AWD003900), Lucerne, Switzerland; AAP Sunstar Innovation Award (AWD007224), Chicago, Illinois; Department of Periodontics and Oral Medicine Clinical Research Supplemental Research Grant, Ann Arbor, Michigan; and School of Dentistry Research Collaborative Award, Ann Arbor, Michigan. The authors report no conflicts of interest related to this study.

\section{AUTHOR CONTRIBUTIONS}

Drs. Tattan and Sinjab contributed to data collection and data analysis, as well as to manuscript writing. Prof. Arnett contributed to data collection and the manuscript revision. Prof. Lee contributed to statistical data analysis. Profs. Chan and Kripfgans contributed to the study conception and work design as well as manuscript revision, and final approval. Prof. Kripfgans also contributed by acquiring the used device. Profs. Wang and Oh contributed to the study assurance and manuscript revision, they also oversee the study.

\section{ORCID}

Mustafa Tattan (iD https://orcid.org/0000-0001-7498-8064

Tae-Ju Oh (D) https://orcid.org/0000-0003-0575-9502

Hom-Lay Wang (D) https://orcid.org/0000-0003-4238-1799 
Hsun-Liang Chan (iD https://orcid.org/0000-0001-5952-0447 Oliver D. Kripfgans

https://orcid.org/0000-0003-2905-1496

\section{R E F E R E N C ES}

1. Ghorayeb SR, Bertoncini CA, Hinders MK. Ultrasonography in dentistry. IEEE Trans Ultrason Ferroelectr Freq Control. 2008;55:1256-1266.

2. Muller HP, Barrieshi-Nusair KM, Kononen E. Repeatability of ultrasonic determination of gingival thickness. Clin Oral Investig. 2007;11:439-442.

3. Muller HP, Kononen E. Variance components of gingival thickness. J Periodontal Res. 2005;40:239-244.

4. Tzoumpas M, Mohr B, Kurtulus-Waschulewski I, Wahl G. The use of high-frequency ultrasound in the measurement of thickness of the maxillary attached gingiva. Int J Prosthodont. 2015;28: 374-382.

5. Furtak A, Leszczynska E, Sender-Janeczek A, Bednarz W. The repeatability and reproducibility of gingival thickness measurement with an ultrasonic device. Dent Med Probl. 2018;55:281-288.

6. Rajpoot N, Nayak A, Nayak R, Bankur PK. Evaluation of variation in the palatal gingival biotypes using an ultrasound device. J Clin Diagn Res. 2015;9:ZC56-60.

7. Lynch JE, Hinders MK. Ultrasonic device for measuring periodontal attachment levels. Rev Sci Instrum. 2002;73:2686-2693.

8. De Bruyckere T, Eghbali A, Younes F, De Bruyn H, Cosyn J. Horizontal stability of connective tissue grafts at the buccal aspect of single implants: a 1-year prospective case series. J Clin Periodontol. 2015;42:876-882.

9. Chifor R, Badea ME, Hedesiu M, Chifor I. Identification of the anatomical elements used in periodontal diagnosis on $40 \mathrm{MHz}$ periodontal ultrasonography. Rom J Morphol Embryol. 2015;56:149153.

10. Chifor R, Badea ME, Vesa SC, Chifor I. The utility of $40 \mathrm{MHz}$ periodontal ultrasonography in the assessment of gingival inflammation evolution following professional teeth cleaning. Med Ultrason. 2015;17:34-38.

11. Palou ME, McQuade MJ, Rossmann JA. The use of ultrasound for the determination of periodontal bone morphology. J Periodontol. 1987;58:262-265

12. Tsiolis FI, Needleman IG, Griffiths GS. Periodontal ultrasonography. J Clin Periodontol. 2003;30:849-854.

13. Chifor R, Hedesiu M, Bolfa P, et al. The evaluation of $20 \mathrm{MHz}$ ultrasonography, computed tomography scans as compared to direct microscopy for periodontal system assessment. Med Ultrason. 2011;13:120-126.

14. Nguyen KC, Le LH, Kaipatur NR, Major PW. Imaging the cementoenamel junction using a 20-mhz ultrasonic transducer. Ultrasound Med Biol. 2016;42:333-338.

15. Nguyen KT, Le LH, Kaipatur NR, Zheng R, Lou EH, Major $\mathrm{PW}$. High-resolution ultrasonic imaging of dento-periodontal tissues using a multi-element phased array system. Ann Biomed Eng. 2016;44:2874-2886.

16. Mahmoud AM, Ngan P, Crout R, Mukdadi OM. High-resolution 3D ultrasound jawbone surface imaging for diagnosis of periodontal bony defects: an in vitro study. Ann Biomed Eng. 2010;38:34093422 .
17. Chan HL, Wang HL, Fowlkes JB, Giannobile WV, Kripfgans OD. Non-ionizing real-time ultrasonography in implant and oral surgery: a feasibility study. Clin Oral Implants Res. 2017;28:341-347.

18. Chan HL, Sinjab K, Chung MP, et al. Non-invasive evaluation of facial crestal bone with ultrasonography. PLoS One. 2017; 12:e0171237.

19. Nguyen KT, Pacheco-Pereira C, Kaipatur NR, Cheung J, Major PW, Le LH. Comparison of ultrasound imaging and cone-beam computed tomography for examination of the alveolar bone level: a systematic review. PLoS One. 2018;13:e0200596.

20. Chan HL, Sinjab K, Li J, Chen Z, Wang HL, Kripfgans OD. Ultrasonography for noninvasive and real-time evaluation of peri-implant tissue dimensions. J Clin Periodontol. 2018;45:986-995.

21. Hallgren KA. Computing inter-rater reliability for observational data: an overview and tutorial. Tutor Quant Methods Psychol. 2012;8:23-34.

22. Morgan CJ, Aban I. Methods for evaluating the agreement between diagnostic tests. J Nucl Cardiol. 2016;23:511-513.

23. Bland JM, Altman DG. Statistical methods for assessing agreement between two methods of clinical measurement. Lancet. 1986;1:307310.

24. Eghbali A, De Bruyn H, Cosyn J, Kerckaert I, Van Hoof T. Ultrasonic assessment of mucosal thickness around implants: validity, reproducibility, and stability of connective tissue grafts at the buccal aspect. Clin Implant Dent Relat Res. 2016;18:51-61.

25. Claffey N, Shanley D. Relationship of gingival thickness and bleeding to loss of probing attachment in shallow sites following nonsurgical periodontal therapy. J Clin Periodontol. 1986;13:654657.

26. Olsson M, Lindhe J. Periodontal characteristics in individuals with varying form of the upper central incisors. J Clin Periodontol. 1991;18:78-82.

27. Chan HL, Chun YH, MacEachern M, Oates TW. Does gingival recession require surgical treatment. Dent Clin North Am. 2015;59:981-996.

28. Fu JH, Yeh CY, Chan HL, Tatarakis N, Leong DJ, Wang HL. Tissue biotype and its relation to the underlying bone morphology. $J$ Periodontol. 2010;81:569-574.

29. Chao YC, Chang PC, Fu JH, Wang HL, Chan HL. Surgical site assessment for soft tissue management in ridge augmentation procedures. Int J Periodontics Restorative Dent. 2015;35: e75-83.

30. Fu JH, Lee A, Wang HL. Influence of tissue biotype on implant esthetics. Int J Oral Maxillofac Implants. 2011;26:499-508.

31. Lin GH, Chan HL, Wang HL. Effects of currently available surgical and restorative interventions on reducing midfacial mucosal recession of immediately placed single-tooth implants: a systematic review. J Periodontol. 2014;85:92-102.

32. Bhaskar V, Chan HL, MacEachern M, Kripfgans OD. Updates on ultrasound research in implant dentistry: a systematic review of potential clinical indications. Dentomaxillofac Radiol. 2018;47:20180076.

33. De Rouck T, Eghbali R, Collys K, De Bruyn H, Cosyn J. The gingival biotype revisited: transparency of the periodontal probe through the gingival margin as a method to discriminate thin from thick gingiva. J Clin Periodontol. 2009;36:428-433.

34. Kan JY, Morimoto T, Rungcharassaeng K, Roe P, Smith DH. Gingival biotype assessment in the esthetic zone: visual versus direct measurement. Int J Periodontics Restorative Dent. 2010;30:237243. 
35. Timock AM, Cook V, McDonald T, et al. Accuracy and reliability of buccal bone height and thickness measurements from cone-beam computed tomography imaging. Am J Orthod Dentofacial Orthop. 2011;140:734-744.

36. Braut V, Bornstein MM, Belser U, Buser D. Thickness of the anterior maxillary facial bone wall-a retrospective radiographic study using cone beam computed tomography. Int J Periodontics Restorative Dent. 2011;31:125-131.

37. Vera C, De Kok IJ, Reinhold D, et al. Evaluation of buccal alveolar bone dimension of maxillary anterior and premolar teeth: a cone beam computed tomography investigation. Int J Oral Maxillofac Implants. 2012;27:1514-1519.

38. Wang HM, Shen JW, Yu MF, Chen XY, Jiang QH, He FM. Analysis of facial bone wall dimensions and sagittal root position in the maxillary esthetic zone: a retrospective study using cone beam computed tomography. Int J Oral Maxillofac Implants. 2014;29:11231129.

39. Frost NA, Mealey BL, Jones AA, Huynh-Ba G. Periodontal biotype: gingival thickness as it relates to probe visibility and buccal plate thickness. J Periodontol. 2015;86:1141-1149.

40. Rubin JM, Adler RS, Fowlkes JB, et al. Fractional moving blood volume: estimation with power Doppler ultrasound. Radiology. 1995;197:183-190.
41. Zoellner H, Chapple CC, Hunter N. Microvasculature in gingivitis and chronic periodontitis: disruption of vascular networks with protracted inflammation. Microsc Res Tech. 2002;56:15-31.

42. Lin CY, Chen F, Hariri A, et al. Photoacoustic imaging for noninvasive periodontal probing depth measurements. J Dent Res. 2018;97:23-30

43. Moore C, Bai Y, Hariri A, et al. Photoacoustic imaging for monitoring periodontal health: a first human study. Photoacoustics. 2018; $12: 67-74$

\section{SUPPORTING INFORMATION}

Additional supporting information may be found online in the Supporting Information section at the end of the article.

How to cite this article: Tattan M, Sinjab K, Lee E, et al. Ultrasonography for chairside evaluation of periodontal structures: A pilot study. J Periodontol. 2020; 91:890-899. https://doi.org/10.1002/JPER.19-0342 